\title{
Caterine Galaz V., Rolando Poblete M. y Carla Frías O., Políticas Públicas e Inmigración ¿Posibilidades de inclusión efectiva en Chile?, Santiago, Editorial Universitaria, 2017, 130 pp.
}

\author{
Reseña por Andrés Bianchetti Saavedra*
}

Perfiles Latinoamericanos, 27(53) | 2019

DOI: $10.18504 / \mathrm{pl} 2753-017-2019$

Jos recientes y crecientes movimientos migratorios hacia Chile de las últimas décadas han configurado un nuevo escenario social, espacial y económico que representa nuevos desafíos para la sociedad chilena en términos de inclusión y equidad social. Es en este contexto en el que desde la academia han surgido también voces que han indicado la necesidad de repensar el modo en que chilenos y chilenas asumen esta realidad que impone nuevos desafíos en cuanto a la relación que se establece con la diversidad cultural, y la manera en que el país construye sus políticas públicas y es capaz de incorporar efectivamente en ellas a estos nuevos grupos de personas provenientes desde distintos puntos de Latinoamérica e incluso de Europa. Es en este marco que Caterine Galaz Valderrama, Rolando Poblete Melis y Carla Frías Ortega han publicado Políticas Públicas e inmigración ¿Posibilidades de inclusión efectiva en Chile?, una obra que entrega una visión general respecto del estado del arte de la situación de los migrantes en Chile, principalmente en cuanto al acceso a los servicios y a la oferta social del Estado, complementando esto con los elementos obstaculizadores y facilitadores de dicha relación.

En el capítulo 1, "La comunidad inmigrada en Chile", los autores presentan las migraciones como un fenómeno global. Ofrecen datos que lo caracterizan en su condición actual y en comparación con otras épocas históricas. Asimismo, se recogen algunas de las características que transforman a Chile en un país

\footnotetext{
* Antropólogo por la Universidad Austral de Chile y Magister en Educación por la Universidad Metropolitana de Ciencias de la Educación. Profesor Asistente en la Universidad San Sebastián, Concepción, Chile | abianchettis@docente.uss.cl
} 
atractivo para el migrante y destacan las cifras que lo sitúan en la media mundial de población inmigrante residente, establecida en torno al 3\%, con tasas porcentuales que van entre el 2.3 y $2.7 \%$, dependiendo de la fuente consultada. Una inmigración mayoritariamente femenina, la preponderante presencia de hogares biparentales en el país, la importante cantidad de personas jóvenes junto con el significativo aumento de colombianos y bolivianos son, entre otros, datos destacados en el capítulo por los autores, los cuales permiten caracterizar el fenómeno. Lo anterior se complementa con estadísticas sociales que dan cuenta de mayores ingresos en los hogares migrantes, pero con condiciones de vulnerabilidad acentuadas cuando se considera la situación desmejorada de hacinamiento y de acceso a la vivienda propia en comparación con las familias chilenas. De este modo, se establece que al medir la pobreza desde múltiples dimensiones existe un porcentaje mayor de familias pobres migrantes en comparación con las chilenas. Además, un importante dato que se debe valorar cuando se analiza la desigualdad presente en Chile entre nacionales y extranjeros se refiere a los niveles de escolaridad de los migrantes que, en todos los casos, con excepción de bolivianos, son mayores en promedio que los de la población chilena, situación que puede distorsionar algunos datos en la medición de la pobreza.

En el capítulo 2, “Simple recepción o inclusión social?”, Galaz, Poblete y Frías analizan el rol del Estado en materias migratorias, en especial desde un enfoque de derechos, especificando los ámbitos de acción de aquel en la materia, desde la formulación de reglamentos hasta el diseño de políticas de integración. Se destacan, por lo tanto, las metas por alcanzar a nivel colectivo: "Los desafíos sociales y culturales, políticos y económicos que conlleva la evidencia de la diversidad sociocultural en algunas sociedades como la chilena, requiere poner atención a la manera en que se piensa la cohesión social considerando los ejes de diferenciación que se vuelven explícitos con la residencia de personas inmigradas" (p. 26). Así, los autores transitan hacia la implementación de la inclusión social de los migrantes señalando indicaciones para que este proceso sea exitoso:

Pensar la inclusión social de cualquier persona o colectivo pasaría pues por diversos niveles en cuanto: a) acceso garantizado a la ciudadanía y a los derechos económicos, políticos y sociales así como a las posibilidades de participación efectiva; b) la conexión y solidez de las redes de reciprocidad social, ya sean estas de carácter afectivo, familiar, vecinal, comunitario; c) finalmente la inclusión implicaría participar del espacio de la producción económica y muy especialmente del mercado de trabajo en igualdad de condiciones (p. 27).

Posteriormente, los autores centran su discusión en torno al concepto de ciudadanía; cuestionan sus elementos modernos en el escenario mundial actual 
caracterizado por el dinamismo y lo difuso e inestable de las fronteras culturales. De esta forma comienzan a desarrollar lo que denominan ciudadanía intercultural, en el que la dignidad de la persona y el respeto a los derechos fundamentales constituyen sus elementos centrales.

En el mismo capítulo, Galaz, Poblete y Frías apoyan la idea de que las políticas públicas son una poderosa herramienta que contribuye a consolidar la condición de ciudadano en el migrante y a lograr su efectiva inclusión social: "Las políticas inciden directamente en las posibilidades efectivas de inclusión social de las personas migradas, al desarrollar y/o reproducir actuaciones y discursos en cuanto al reconocimiento enunciativo, la incorporación sociocultural y la igualdad de oportunidades de este colectivo" (p. 30). Los autores ven como condición de una política pública inclusiva su vinculación con la perspectiva de derechos humanos, de modo que se garantice la condición ciudadana del migrante y, en el ejercicio práctico de esta ciudadanía, su efectiva inclusión en la sociedad receptora.

El capítulo concluye insistiendo en que al migrante hay que verlo, desde la construcción de las políticas públicas, como un sujeto de necesidades económicas y como un ser integral que se desenvuelve en distintas esferas de la vida social y política, situación que, a juicio de los autores, debe reflejarse en las acciones que desde el Estado se orientan hacia este segmento de la población.

El tercer capítulo del libro, "Experiencias internacionales ante los flujos migratorios", describe el modo en que en Argentina, Uruguay, Ecuador y Costa Rica, en América Latina, y España y Alemania, en la Unión Europea, han abordado el tema migratorio. Según los autores "las regulaciones legales que cada país ha impuesto se inscriben en visiones políticas acerca del rol de los/as migrados/as y acerca del propio rol de las sociedades de acogida" (p. 37). En el caso de la Unión Europea, detallan que existe un marco común que regula la inmigración, al menos en principios fundamentales para los países que la integran y que representan un punto de inicio para las regulaciones locales de cada país. En este sentido, los autores señalan que "su finalidad es asegurar que la inmigración legal contribuya al desarrollo socioeconómico de la Unión Europea, se refuerce la cooperación con países no pertenecientes a ella, y se aborde de manera eficaz la inmigración ilegal y la trata de seres humanos" (p. 38). Destacan que en el caso de la Unión Europea, el discurso se establece sobre todo desde la integración del migrante, aunque no desconocen las dificultades que este proceso tiene debido a las manifestaciones de racismo y xenofobia aún presentes en los países europeos. Por otra parte, destacan la especial atención que en la Unión Europea se ha dedicado a la problemática del tráfico de migrantes y trata de personas, estableciendo incluso sistemas de residencia para los indocumentados que colaboren con el desmantelamiento de estas mafias. 
Distinto es el caso de América Latina donde, pese a los esfuerzos del mercado común del sur (Mercosur), cada país ha elaborado un camino propio.

En términos específicos, los autores describen brevemente el caso español, donde desde 2007, y producto de la crisis económica, existe un sistema de copago que permite tanto a nacionales como a extranjeros acceder a servicios y prestaciones sociales. Luego de esto, dedican un lacónico espacio al caso alemán, del que se describen las condiciones que un extranjero debe cumplir para que pueda residir en el país y los derechos que posee, luego de haber realizado anteriormente un escueto recorrido histórico de algunos hitos importantes en la recepción de migrantes desde el siglo xx hasta la actualidad.

En cuanto a los países latinoamericanos, se analiza el caso argentino del que se destaca su carácter integrador y abierto a la migración desde una perspectiva de derechos humanos. Se detallan las redes de apoyo institucionales con las que cuenta el migrante, haciendo hincapié en la condición de igualdad legal que el migrante posee, por la sola condición de persona, en el territorio argentino. A continuación, se da cuenta de la situación de Costa Rica, país que también garantiza derechos a los migrantes, aun cuando, a juicio de los autores, introduce restricciones ausentes en el caso argentino. A modo de ejemplo se puede mencionar que Costa Rica define qué áreas laborales son prioritarias para el país y sobre esa base identifican los trabajos que pueden desarrollar los migrantes. Del mismo modo, el país ha creado un fondo que recibe aportes de los migrantes y que son invertidos en las políticas públicas de las que son destinatarios. Posteriormente se da cuenta del caso de Uruguay destacando algunas similitudes con el argentino, aun cuando en el primero hay restricciones en lo laboral para los extranjeros que se encuentran en situación de "no residente". Por último, se describe el caso de Ecuador donde si bien la política se encuentra centrada en los nacionales emigrantes, en los últimos tiempos se ha comenzado a refocalizar la atención en los migrantes que han arribado al país, lo anterior producto del aumento de ciudadanos de Perú y Colombia residiendo en territorio ecuatoriano. Este capítulo concluye con una breve reflexión sobre el diseño de las políticas públicas en relación a la migración y cómo estas aún deben afrontar profundas desigualdades en las distintas sociedades.

El capítulo 4, "Gestión pública, gestión de la inmigración y etnografía del Estado", analiza el papel del Estado en cuanto a la construcción de políticas públicas destinadas a la población migrante, asignando un lugar central a la "integración" de estos colectivos en la sociedad receptora. En esta línea, los autores reflexionan sobre el estado de las políticas públicas vinculadas a la temática migratoria concluyendo que Chile no posee una política pública explícita destinada a abordar el fenómeno de la migración y los acontecimientos que se le vinculan. Luego se detallan las convenciones internacionales - y su contenido 
central — que Chile ha ratificado en materia migratoria, para luego analizar la legislación nacional, que data de 1975, y que según los autores, establece "la doctrina de la seguridad nacional por sobre los derechos de las personas" (p. 69) dado el contexto histórico en el que surge esta normativa. De este modo, son claros en señalar la urgente necesidad de actualizar la ley vigente, adaptándola al contexto actual y diseñándola en concordancia con los tratados internacionales que Chile ha ratificado. Para los autores también es fundamental "modificar el concepto de migrante que está sobre la base de la legislación, mutando su sentido de potencial amenaza a otro que diga relación con la titularidad de derechos" (p. 70). En el capítulo se destacan los avances en educación y salud orientados a la población migrante, y se dejan en claro los desafíos que aún persisten en cuestiones de vivienda, un área todavía con falencias en cuanto a satisfacción de necesidades básicas de los migrantes. El apartado finaliza analizando el rol de los funcionarios públicos de primera línea en la implementación de las políticas destinadas a los migrantes y el modo en que ellos pueden facilitar u obstaculizar el proceso de inclusión social de esta población. Esta última reflexión se complementa con datos de investigaciones recientes que señalan los altos grados de etnocentrismo y discriminación respecto a los migrantes que están presentes en la sociedad chilena.

En el quinto y último capítulo del libro, "Caminos de inclusión/exclusión: La difícil adaptación de la oferta programática en Chile", se presentan los resultados de una investigación que da cuenta de elementos que facilitan y obstaculizan el acceso a la oferta pública de las personas migrantes en las ciudades de Arica, Antofagasta, Santiago y Punta Arenas, urbes que se caracterizan por las altas tasas de población migrante en relación con el resto del país. En salud, los autores destacan el acceso de niños, niñas, mujeres embarazadas y de todo aquel migrante que presente una urgencia a los servicios de salud, aunque a la vez dan cuenta de una brecha importante en cuanto al amplio acceso a la atención primaria que existe en el país y lo restringido del nivel secundario, situación muchas veces provocada por no poseer el número de identificación otorgado en Chile. Otro elemento que obstaculiza en muchas ocasiones el acceso es el idioma, principalmente entre los haitianos; entonces los nińos menores deben muchas veces ejercer labores de traductores para sus padres. En educación, por otra parte, se da cuenta de que los niños inmigrados pueden acceder universalmente al sistema escolar, independientemente de la situación migratoria de sus progenitores. Sin embargo, todavía se observan varias problemáticas relacionadas con la obtención de la documentación de los menores y con la inexistencia de la cédula de identidad que se otorga en Chile, junto con situaciones de discriminación que los migrantes en los centros educativos de parte de sus pares, en particular originadas por su color de piel. En cuanto 
a la vivienda, los autores visualizan este aspecto como el más crítico para los migrantes dados los altos grados de hacinamiento y las dificultades para optar a los programas estatales. No obstante, reconocen avances en la posibilidad de postular al subsidio habitacional luego de obtener la residencia definitiva en Chile, como también la asesoría legal y social que algunos municipios entregan para poder habitar un espacio digno. Por último, en relación con el trabajo, se detectan irregularidades y desigualdades que la población migrante vive en comparación con la nacional, aun cuando se reconocen avances por los que se facilita la contratación con la creación de la "visa temporaria por motivos laborales" que evita antiguos trámites administrativos que dificultaban la contratación. El capítulo finaliza con la reflexión sobre los obstáculos procedimentales que enfrentan los migrantes en el acceso a la oferta pública, debido a la falta de información de los funcionarios públicos en cuanto a sus derechos sociales y legales y como consecuencia de los prejuicios y estereotipos que existen sobre los migrantes en una parte importante de la sociedad chilena.

Para concluir la publicación, los autores entregan una breve reflexión en la que destaca la idea sobre la necesidad de que las políticas públicas orientadas a migrantes en Chile transiten hacia un enfoque de derechos humanos, a fin de llevar la situación de la población migrante a un estado de real inclusión, mejorando así su calidad de vida y condiciones sociales en el país receptor.

El libro de Catherine Galaz, Rolando Poblete y Carla Frías es una buena aproximación para determinar la situación de Chile en el contexto regional latinoamericano respecto al fenómeno migratorio. Las comparaciones y los datos presentados dimensionan los puntos comunes y distantes en relación con otros casos de la región, junto con abrir brechas y discusiones pendientes que este país tiene debido a que es un destino reciente de la migración proveniente sobre todo de Bolivia, Colombia, Haití y República Dominicana, entre otras naciones. En este sentido, el libro establece los nuevos desafíos migratorios que la sociedad chilena debe resolver para equipararse a la región, en un marco en el que el elemento principal consiste en construir políticas públicas basadas en un enfoque de derechos humanos, situación que, según los autores, se encuentra avanzada en varios países vecinos.

La publicación contiene interesantes elementos de diagnóstico y crítica de la situación de las políticas públicas destinadas a los migrantes en Chile; sin embargo, sería importante contar con una mayor cantidad de propuestas que permitan una futura construcción de esas políticas, basadas en la teoría que se desarrolla en el texto reseñado. Un aporte relevante sería entregar mayores términos de referencia concretos en cuanto a propuestas de diseño y construcción de políticas públicas destinadas a los migrantes llegados a Chile. Aun cuando existen algunas ideas, parecen más bien incipientes en un escenario 
donde los debates continúan y no tienen un destino claro y definitivo en la sociedad chilena.

Politicas Públicas e Inmigración ¿Posibilidades de inclusión efectiva en Chile? es un libro que entrega una visión general del estado de la migración en Chile. Más que proporcionar una gran de cantidad de datos estadísticos, la publicación se enfoca en dar cuenta del hacer cotidiano de los migrantes en Chile en su relación con el aparato estatal y el acceso a los beneficios públicos. Pero este libro es un estímulo que permite debatir sobre cómo se están desarrollando los procesos de inclusión social en Chile y cómo estos se reflejan en las políticas públicas locales, de forma tal que eso da pauta para evaluar su efectividad y pertinencia. En este sentido, la publicación es un aporte al debate en Chile acerca de cómo se debe atender la diversidad cultural que hoy en día se expresa en el país. Asimismo, deja preguntas abiertas cuya respuesta debe elaborarse desde la sociedad en su conjunto, con el fin de construir una convivencia inclusiva, respetuosa y digna entre todos los que habitan hoy en Chile. 